the famous TV series 'Star Trek' is characterised by his lack of emotions and brilliant ruthless logic. The film 'Bladerunner' based on the book Do Androids Dream of Electric Sheep? by Philip K. Dick, like Terminator 2, explored the development of emotions in robots. In the film 'Being There', Peter Sellers plays the autistic gardener Chancy whose literal and simple statements are mistakenly understood in metaphorical terms and are then seen as visionary; he, like Jesus, walks on water at the end of the film. And more recently Dustin Hoffman played the autistic 'idiot savant' in 'Rainman'. The Who's rock opera 'Tommy', about a "deaf, dumb and blind kid" is intended to depict an autistic child who becomes a pinball wizard.

Even the classic fairy tales Sleeping Beauty and Snow White popularised by brothers Grimm, have been interpreted to be about beautiful children somehow unavailable, (as are many autistic children described by their parents) who need only a kiss from a prince to be awoken. So the Terminator is shown only to need the magic of the young boy's devotion and love to start experiencing and understanding emotions.

For a relatively rare disorder, autism has a high profile both overtly, and more discreetly in films like Terminator 2.

Harper House Children's Service

Radlett, Herts W97 7HU

\section{Molecular genetic research into Alzheimer's disease}

DeAR Sirs

Reports in the national press about the break-up of the Alzheimer's disease research group at St Mary's
Hospital Paddington have given the misleading impression that this means the end of molecular genetic research into Alzheimer's disease in the UK. The Mental Health Foundation has just funded us so that the work can continue in this country and we are now busy trying to identify suitable families where more than one person suffers from the disease. It does not matter which relatives are affected or at what age the illness developed. All we need for our research is to conduct a brief interview and to collect a small sample of blood. We will be happy to travel anywhere within the UK to do so.

If any of your readers know of families that might be suitable for our research, then we would be most grateful if they could contact us at the address below.

Department of Psychological Medicine

MALCOLM LidDELL Michael OWEN

University of Wales College of Medicine

Heath Park, Cardiff, CF4 4XN

\section{Use of section 5(2)}

\section{DeAR Sirs}

Which section should be used when transferring a patient from an NHS owned and 24 hour staffed Psychiatric Home in the community to the main hospital? The least restrictive Section would of course be a $5(2)$ but if the Home is regarded as the patient's home than a 5(2) would not be appropriate.

\section{Carlton Hayes Hospital}

D. I. KHoOSAL

Narborough

Leicestershire LE9 SE5

\section{Scientific meeting}

'Psychoanalytic Ideas and Developmental Observations': a one day scientific meeting under the auspices of the Anna Freud Centre and the Psychoanalysis Unit, University College London, in honour of Dr George S. Moran, will be held on 27 June 1992 at the Edward Lewis Theatre, Middlesex Hospital Medical School, Windeyer Building, 46 Cleveland
Street, London W1. Admission is free but the number of places is limited. Those interested in attending must contact The Conference Secretary, Psychoanalysis Unit, University College London, 26 Bedford Way, London WCIH OAP as soon as possible (telephone $071580 \quad 6902$-answering machine; fax 0712894800 ). 